\title{
T cells become licensed in the lung to enter the central nervous system
}

\author{
Francesca Odoardi ${ }^{1}$, Christopher $\mathrm{Sie}^{1}$, Kristina Streyl ${ }^{2}$, Vijay K. Ulaganathan ${ }^{2}$, Christian Schläger ${ }^{1}$, Dmitri Lodygin ${ }^{1}$, \\ Klaus Heckelsmiller ${ }^{2}$, Wilfried Nietfeld ${ }^{3}$, Joachim Ellwart ${ }^{4}$, Wolfgang E. F. Klinkert ${ }^{2}$, Claudio Lottaz ${ }^{5}$, Mikhail Nosov ${ }^{6}$, \\ Volker Brinkmann ${ }^{7}$, Rainer Spang ${ }^{5}$, Hans Lehrach ${ }^{3}$, Martin Vingron $^{3}$, Hartmut Wekerle ${ }^{2}$, Cassandra Flügel-Koch ${ }^{8}$ \\ \& Alexander Flügel ${ }^{1}$
}

The blood-brain barrier (BBB) and the environment of the central nervous system (CNS) guard the nervous tissue from peripheral immune cells. In the autoimmune disease multiple sclerosis, myelin-reactive $T$-cell blasts are thought to transgress the $\mathbf{B B B}^{1,2}$ and create a pro-inflammatory environment in the CNS, thereby making possible a second autoimmune attack that starts from the leptomeningeal vessels and progresses into the parenchyma ${ }^{3-6}$. Using a Lewis rat model of experimental autoimmune encephalomyelitis, we show here that contrary to the expectations of this concept, T-cell blasts do not efficiently enter the CNS and are not required to prepare the $\mathrm{BBB}$ for immune-cell recruitment. Instead, intravenously transferred $\mathrm{T}$-cell blasts gain the capacity to enter the CNS after residing transiently within the lung tissues. Inside the lung tissues, they move along and within the airways to bronchus-associated lymphoid tissues and lung-draining mediastinal lymph nodes before they enter the blood circulation from where they reach the CNS. Effector T cells transferred directly into the airways showed a similar migratory pattern and retained their full pathogenicity. On their way the $\mathrm{T}$ cells fundamentally reprogrammed their gene-expression profile, characterized by downregulation of their activation program and upregulation of cellular locomotion molecules together with chemokine and adhesion receptors. The adhesion receptors include ninjurin 1, which participates in $\mathrm{T}$-cell intravascular crawling on cerebral blood vessels. We detected that the lung constitutes a niche not only for activated $\mathrm{T}$ cells but also for resting myelin-reactive memory $T$ cells. After local stimulation in the lung, these cells strongly proliferate and, after assuming migratory properties, enter the CNS and induce paralytic disease. The lung could therefore contribute to the activation of potentially autoaggressive $\mathrm{T}$ cells and their transition to a migratory mode as a prerequisite to entering their target tissues and inducing autoimmune disease.

We monitored the invasion of the CNS by green-fluorescentprotein (GFP)-expressing myelin basic protein (MBP)-reactive T cells $\left(\mathrm{T}_{\mathrm{MBP}-\mathrm{GFP}} \text { cells }\right)^{7}$ over the preclinical phase of Lewis rat transfer experimental autoimmune encephalomyelitis (EAE). Only very few early invading pioneer $\mathrm{T}$ cells ${ }^{1,2}$ were detected in the CNS in the first $60 \mathrm{~h}$ after intravenous transfer of activated $\mathrm{T}_{\mathrm{MBP}-\mathrm{GFP}}$ cells $(<100 \mathrm{~T}$ cells per total spinal cord). The bulk of $\mathrm{T}_{\mathrm{MBP}-\mathrm{GFP}}$ cells $\left(>10^{6} \mathrm{~T}\right.$ cells per total spinal cord) started to invade the CNS at the leptomeningeal vessels of the spinal cord 60-84 $\mathrm{h}$ after T-cell transfer, shortly before the onset of clinical symptoms (Fig. 1a and Supplementary Fig. 1a, b) $)^{3,4,8}$. Pro-inflammatory cytokines and adhesion molecules in the CNS became detectable only during the mass T-cell invasion (Supplementary Fig. 1c) $)^{3,9}$
The $\mathrm{T}_{\text {MBP-GFP }}$ cells nearly all disappeared from the blood almost immediately after intravenous infusion. It was not until $48 \mathrm{~h}$ later that a gradual increase of $\mathrm{T}_{\mathrm{MBP}-\mathrm{GFP}}$ cells was observed in the blood and spleen, closely followed by the start of the main invasion of the T cells into the CNS (Fig. 1b). This coincidence of the reappearance of the $\mathrm{T}_{\mathrm{MBP}-\mathrm{GFP}}$ cells in blood and spleen and their invasion into the CNS led us to test whether the re-emerged cells (termed $\mathrm{T}_{\text {migratory }}$ cells) would enter the nervous tissue more efficiently than the initially transferred $\mathrm{T}_{\mathrm{MBP}-\mathrm{GFP}}$ cell blasts ( $\mathrm{T}_{\text {blast }}$ cells). To do this, we prepared an anastomosis between the blood circulations of two animals, one of
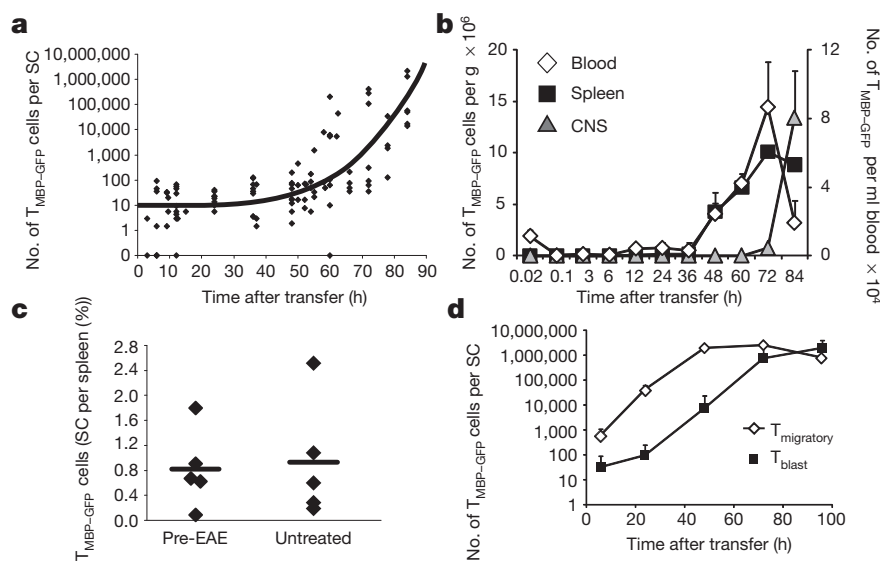

Figure $1 \mid \mathrm{T}_{\text {migratory }}$ cells but not $\mathrm{T}_{\text {blast }}$ cells home efficiently into the CNS. a, Invasion of $T_{M B P-G F P}$ cells into the CNS during transfer EAE. $T_{M B P-G F P}$ cells were quantified in the total spinal cord (SC) at the indicated time points after T-cell transfer by cytofluorometry. Each diamond represents a single animal. b, Transferred $\mathrm{T}_{\mathrm{MBP}-\mathrm{GFP}}$ cells reappear in the blood and spleen shortly before CNS invasion. Cytofluorometric quantification of $\mathrm{T}_{\mathrm{MBP}-\mathrm{GFP}}$ cells. Means \pm 1 s.d. of 4 animals are shown. Representative data of eight independent experiments, including at least three animals per time point. c, Blood-derived $\mathrm{T}_{\text {migratory }}$ cells of pre-EAE animals enter the CNS of naïve rats. A blood connection was established linking the tail arteries of an untreated animal with an animal that had received $\mathrm{T}_{\text {blast }}$ cells $48 \mathrm{~h}$ beforehand (pre-EAE animal). Twelve hours later the numbers of $\mathrm{T}_{\mathrm{MBP}-\mathrm{GFP}}$ cells were determined by cytofluorometry. Shown are relative values of $\mathrm{T}_{\mathrm{MBP}-\mathrm{GFP}}$ cells in the CNS versus spleens of five pairs of animals. $\mathbf{d}$, Spleen-derived $\mathrm{T}_{\text {migratory }}$ cells efficiently infiltrate the CNS. $\mathrm{T}_{\text {blast }}$ cells or $\mathrm{T}_{\text {migratory }}$ cells (isolated from spleen $60 \mathrm{~h}$ after transfer) were transferred in naive animals. Numbers of $\mathrm{T}_{\mathrm{MBP}-\mathrm{GFP}}$ cells were quantified by cytofluorometry in total spinal cord at the indicated time points after T-cell transfer. Means \pm 1 s.d. of triplicate measurements. Representative data from at least six independent experiments are shown. 
which had received $\mathrm{T}_{\text {blast }}$ cells $48 \mathrm{~h}$ beforehand (pre-EAE animal) and the other was a naïve rat that was not pre-treated (Supplementary Fig. 2a). Interestingly, $\mathrm{T}_{\mathrm{MBP}-\mathrm{GFP}}$ cells passing through the blood shunt within $12 \mathrm{~h}$ after anastomosis infiltrated the CNS of the animal that was not pre-treated in similar frequencies to those of the pre-EAE animal (Fig. 1c). Furthermore, in contrast to $\mathrm{T}_{\text {blast }}$ cells, $\mathrm{T}_{\text {migratory }}$ cells isolated from the spleen ( $60 \mathrm{~h}$ after $\mathrm{T}$-cell transfer) readily immigrated into the inflamed CNS and, more importantly, into the CNS of animals that were not pre-treated (Fig. 1d and Supplementary Fig. 2b-e). Intravital two-photon microscopy revealed that $\mathrm{T}_{\text {migratory }}$ cells were crawling on the meningeal vessels within minutes after intravenous transfer. Twenty-four hours later, the $\mathrm{T}_{\text {migratory }}$ cells had transgressed the vessel walls and were moving throughout the leptomeningeal surface and deep within the CNS parenchyma, like T cells usually do 3 to 4 days after transfer of $\mathrm{T}_{\text {blast }}$ cells (Supplementary Fig. 2e-h and Supplementary Movie 1$)^{6,10}$. $\mathrm{T}_{\text {migratory }}$ cells in the CNS upregulated interleukin-2 (IL-2) receptor, OX40, interferon- $\gamma$ (IFN- $\gamma$ ) and IL-17, indicative of a recent antigen encounter and reactivation within the CNS, the trigger for generalized parenchymal inflammation and disease (Supplementary Fig. 2i-k) ) $^{3,4,6,11}$. Beginning $24 \mathrm{~h}$ after T-cell transfer the animals developed the first clinical signs of weight loss, followed $24 \mathrm{~h}$ later by overt paralytic disease; approximately $48 \mathrm{~h}$ earlier than in the typical transfer EAE (Supplementary Fig. 2l).

To identify the homing niches of $\mathrm{T}_{\text {blast }}$ cells after intravenous transfer, we analysed whole body sections of animals, complemented by a

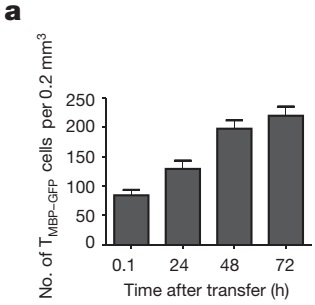

b

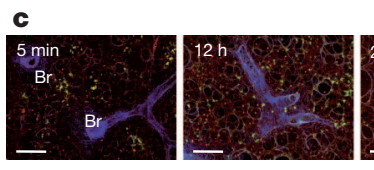

d

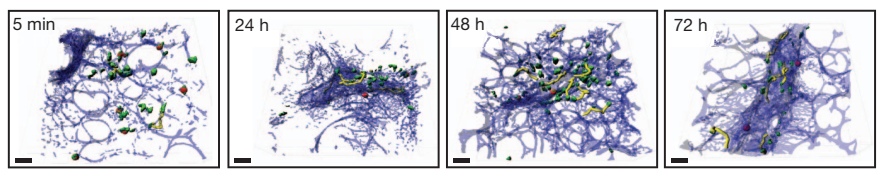

Figure 2 The lung as a homing and reactivation site of $T_{M B P-G F P}$ cells. a, b, Quantification of lung infiltration by $\mathrm{T}_{\mathrm{MBP}-\mathrm{GFP}}$ cells at the indicated time points after transfer of $\mathrm{T}_{\text {blast }}$ cells (a). Cells were counted from two-photonmicroscopy overview images of acute lung slices. Shown are means and s.e.m. from at least three experiments. Lung-derived $\mathrm{T}_{\text {migratory }}$ cells efficiently enter the naïve CNS (b). $1 \times 10^{6} \mathrm{~T}_{\text {migratory }}$ cells isolated from lung $48 \mathrm{~h}$ after T-cell transfer were intravenously injected into naive animals; $24 \mathrm{~h}$ later $\mathrm{T}_{\mathrm{MBP}-\mathrm{GFP}}$ cells were quantified by cytofluorometry. Means \pm 1 s.d. of three animals. Representative data from two independent experiments are shown. LNs, lymph nodes; Med LNs, mediastinal lymph nodes. c, Homing within the lung visualized by two-photon-microscopy. Representative two-photonmicroscopy overview images of acute lung slices at the indicated time points after T-cell transfer. Green, $\mathrm{T}_{\mathrm{MBP}-\mathrm{GFP}}$ cells; red, autofluorescent background and erythrocytes; blue, collagen fibres. Br, bronchial structures. Scale bars, 100 $\mu \mathrm{m}$. d, Motility of $\mathrm{T}_{\mathrm{MBP}-\mathrm{GFP}}$ cells within the lung over time. Three-dimensional reconstructions of representative two-photon-microscopy time-lapse videos of lung explants at the indicated time points after T-cell transfer. Scale bars, 50 $\mu \mathrm{m}$. Green, $\mathrm{T}_{\mathrm{MBP}-\mathrm{GFP}}$ cells; blue, collagen fibres; red dots, trajectories of stationary cells; yellow lines, trajectories of motile cells. e, $\mathrm{T}_{\mathrm{MBP}-\mathrm{GFP}}$ cells use airways as roads. Snapshots of three-dimensional reconstructed time-lapse videos acquired by two-photon microscopy from lung explants $72 \mathrm{~h}$ after T-cell transfer. The times are in relation to the first displayed frame. Yellow, $\mathrm{T}_{\mathrm{MBP}-\mathrm{GFP}}$ cytofluorometric cell quantifications. At the early time points, almost all of the $\mathrm{T}_{\text {blast }}$ cells were located in the lung (Fig. 2a and Supplementary Fig. 3a, b). Some cells were also found distributed in the mucosa of the small intestine. Thereafter, $\mathrm{T}_{\mathrm{MBP}-\mathrm{GFP}}$ cells accumulated in lungdraining mediastinal lymph nodes, before they appeared in the blood and spleen (Fig. $1 \mathrm{~b}$ and Supplementary Fig. $3 \mathrm{c}$ ). Notably, $\mathrm{T}_{\mathrm{MBP}-\mathrm{GFP}}$ cells extracted from the lung at $48 \mathrm{~h}$ after transfer and injected into naive recipient rats accumulated in the CNS within $24 \mathrm{~h}$, where they displayed signs of activation (Fig. 2b and Supplementary Fig. 3d). Thus, the cells became competent in the lung to enter and to get reactivated within the CNS. This led us to analyse $\mathrm{T}_{\mathrm{MBP}-\mathrm{GFP}}$ cell behaviour within the lung in more detail. Within the first $12 \mathrm{~h}$ after transfer, $\mathrm{T}_{\text {blast }}$ cells were distributed within the peripheral lung parenchyma. Then $24-48 \mathrm{~h}$ after transfer, they moved along bronchial structures and accumulated in areas consisting of densely packed clusters of lymphocytes; that is, bronchus-associated lymphoid tissues (BALT) (Fig. 2c, Supplementary Fig. 3e and Supplementary Movie 2). Interestingly, $\mathrm{T}_{\mathrm{MBP}-\mathrm{GFP}}$ cells significantly increased their velocity during their journey (from $3.7 \mu \mathrm{m} \mathrm{min}^{-1}$ to $5.2 \mu \mathrm{m} \mathrm{min}^{-1}$ ) and at the same time the percentage of arrested cells decreased (from $75 \%$ to 50\%) (Fig. 2d, Supplementary Fig. 3f-h and Supplementary Movie 3). Furthermore, $\mathrm{T}_{\mathrm{MBP}-\mathrm{GFP}}$ cells were regularly located within alveoli and bronchi, and seemed to use the airways as roads (Fig. 2e and Supplementary Movie 4). T cells are known to accumulate in the lung, including the airways, during lung infections and allergic reactions,

e
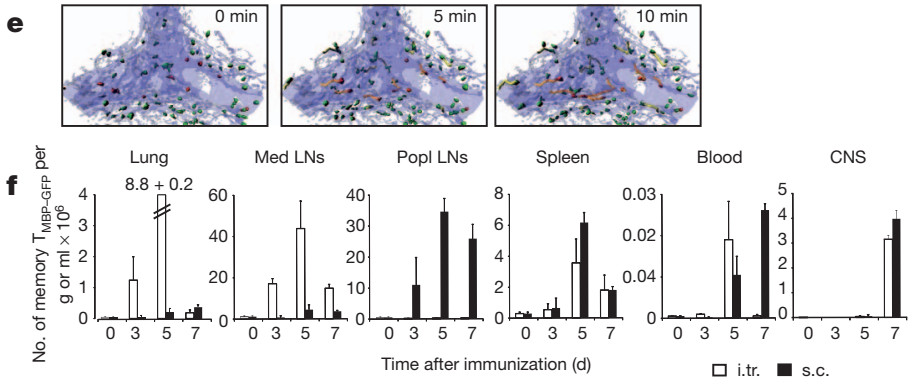

g

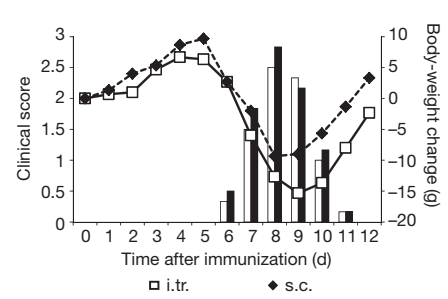

h

cells moving along alveoli and the outer wall of bronchial airways; orange, $\mathrm{T}_{\mathrm{MBP}-\mathrm{GFP}}$ cells moving along the inner wall of airways; blue, collagen fibres rendered semi-transparent to reveal intraluminal cells. f, $\mathbf{g}$, Memory T cells stimulated in the lung induce CNS autoimmunity as efficiently as they do after stimulation in peripheral lymph nodes. $\mathrm{T}_{\mathrm{MBP}-\mathrm{GFP}}$ cells were intraperitoneally transferred into newborns and 10 to 14 weeks later, the animals were MBPimmunized either intratracheally (i.tr.) or subcutaneously (s.c.). Quantification of memory $\mathrm{T}_{\mathrm{MBP}-\mathrm{GFP}}$ cells during $\mathrm{EAE}(\mathbf{f})$. Absolute number of memory $\mathrm{T}_{\mathrm{MBP}-}$ GFP cells was quantified by cytofluorometry at the indicated time points in intratracheally or subcutaneously immunized animals. Popl LNs, popliteal lymph nodes. Means \pm 1 s.d. of duplicate experiments. EAE course in intratracheally or subcutaneously immunized (i.tr. imm. and s.c. imm., respectively) memory animals (g). Clinical score (bars) and body-weight change (lines) were measured daily. Representative data of two independent experiments, with three animals per group. $\mathbf{h}$, Local stimulation of resting $\mathrm{T}_{\mathrm{MBP}-\mathrm{GFP}}$ cells induces CNS disease. Resting $\mathrm{T}_{\mathrm{MBP}-\mathrm{GFP}}$ cells were injected into the trachea or into the footpad of naïve animals. Subsequently the rats were intratracheally or subcutaneously challenged either with MBP in complete Freund's adjuvant or with PBS. Clinical score (bars) and body-weight change (lines) over the EAE course. Representative data of three independent experiments, with at least two animals per group 
although this transepithelial migratory path into the airways has been considered to be a dead end for the cells ${ }^{12}$. Therefore, to test whether $\mathrm{T}$ cells can pass through the airways, we transferred $\mathrm{T}_{\text {blast }}$ cells intratracheally. Similarly to intravenously transferred cells, intratracheally transferred $\mathrm{T}$ cells migrated along the airways and maintained their capacity to emigrate out of the lung and to induce clinical disease (Supplementary Fig. 3i).

The homing of effector $\mathrm{T}$ cells to the lung is not an artefact of transfer EAE. $\mathrm{T}_{\mathrm{MBP}-\mathrm{GFP}}$ cells also accumulated in the lung after 'classical' antigenic stimulation in peripheral lymph nodes after subcutaneous immunization (Supplementary Fig. 4a). Moreover, memory $\mathrm{T}_{\mathrm{MBP}-\mathrm{GFP}}$ cells, which had been embedded in the rat immune system over months, were also found to home and persist within the lung (Supplementary Fig. 4b). Importantly, these cells could readily be activated to become pathogenic: after intratracheal immunization with MBP the cells developed strong signs of activation and, after vigorous amplification within the lung and its draining lymph nodes, they moved into the blood and spleen from where they reached the CNS and triggered a paralytic disease (Fig. 2f, g and Supplementary Fig. 4b-e). Notably, this lung-derived autoimmune response did not differ from the one after stimulation of the memory $\mathrm{T}$ cells in the lymph nodes (Fig. 2f, g and Supplementary Fig. 4c-e). The stimulatory potential of the lung environment was confirmed further by local activation of resting $\mathrm{T}_{\mathrm{MBP}-\mathrm{GFP}}$ cells that had been inserted into the lung by intratracheal transfer. Again, similarly to the stimulation in lymph nodes, the $\mathrm{T}$ cells in the lung underwent effective activation and proliferation following intratracheal administration of antigen, and they gained the capacity to invade the CNS and to evoke clinical EAE (Fig. $2 \mathrm{~h}$ and Supplementary Fig. $4 \mathrm{f}-\mathrm{h}$ ).

Interestingly, $\mathrm{T}_{\mathrm{MBP}-\mathrm{GFP}}$ cells changed their reactivity for chemotactic stimuli during the preclinical phase of transfer EAE. Early ex-vivoisolated $\mathrm{T}_{\mathrm{MBP}-\mathrm{GFP}}$ cells ( $5 \mathrm{~min}$ and $24 \mathrm{~h}$ after T-cell transfer) predominantly migrated towards the homeostatic chemokines CCL19 and CCL21 (Fig. 3a). These migratory preferences of the cells coincided with their migration to bronchial structures and the BALT that express CCL19 and CCL21 (Supplementary Fig. 5a) ${ }^{13}$. Pertussis toxin (PTX), which irreversibly blocks chemokine signalling ${ }^{14}$, significantly reduced their accumulation within the BALT (Supplementary Fig. 5b), supporting the view that the T-cell migration to the bronchial structures and BALT was driven by CCL19 and CCL21. However, PTX pre-treatment did not interfere with the homing of the T cells to the lung and, in contrast to earlier reports about the effect of PTX on T-cell motility in lymph nodes ${ }^{15}$, did not change their locomotion activities (Supplementary Fig. 5c). From $48 \mathrm{~h}$ after transfer onwards, $\mathrm{T}_{\mathrm{MBP}-\mathrm{GFP}}$ cells responded mainly to gradients of inflammatory chemokines, such as CXCL11 and CCL5 (Fig. 3a). This 're-orientation' of the cells was relevant to their ability to home to their target organ: interference with CXCR3 signalling, that is, the corresponding receptor of CXCL11, significantly reduced their CNS invasion and the severity of clinical EAE (Supplementary Fig. 5d). Notably, $\mathrm{T}_{\mathrm{MBP}-\mathrm{GFP}}$ cells left the lung at least partially under the control of sphingolipid signalling. Treatment with FTY720, a receptor agonist that functionally interferes with sphingosine 1-phosphate receptors $(\mathrm{S} 1 \mathrm{P} 1)^{16}$, led to a substantial trapping of the T cells within the BALT, but did not hamper the entry of the cells into the lung or their locomotion behaviour there (Supplementary Fig. 5e, f). FTY720 treatment significantly reduced the numbers of $\mathrm{T}_{\mathrm{MBP}-\mathrm{GFP}}$ cells in the blood and CNS, and delayed and ameliorated clinical EAE (Supplementary Fig. 5g, h), which could well be explained by the arrest of the pathogenic T cells within the lung.

These results suggest that $\mathrm{T}_{\mathrm{MBP}-\mathrm{GFP}}$ cells get equipped during their journey through peripheral environments to enter their target tissue. To characterize these functional changes in more detail, we analysed genome-wide transcriptional profiles of $\mathrm{T}_{\text {blast }}$ cells (before intravenous transfer) and $\mathrm{T}_{\text {migratory }}$ cells (isolated 3 days after $\mathrm{T}$-cell transfer from the spleen) using Affymetrix 230.0 expression arrays. Average linkage cluster analysis (Genesis) revealed $\sim 1800$ upregulated and $\sim 1600$ a

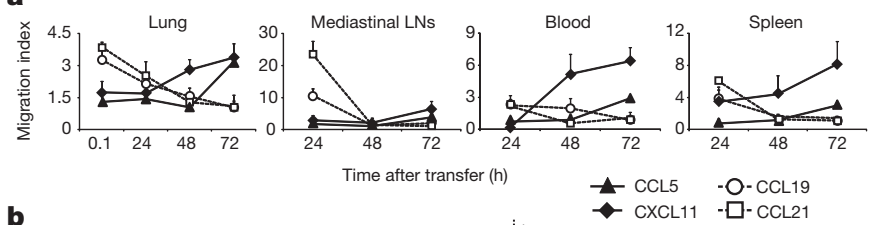

b
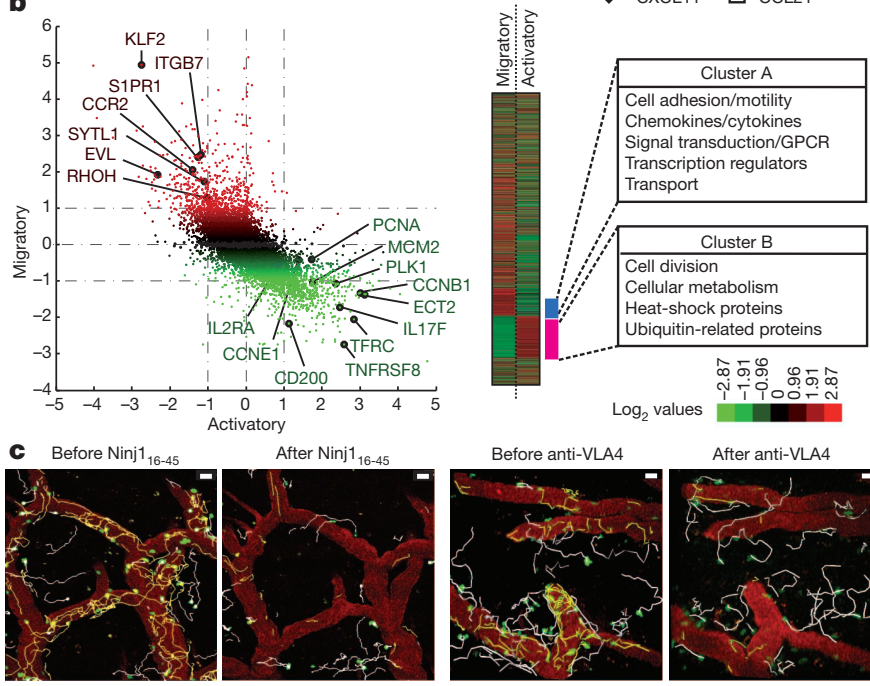

After Ninj $1_{16-4}$
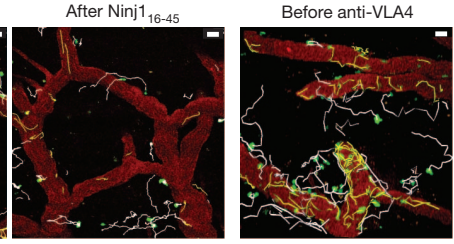

After anti-VLA4
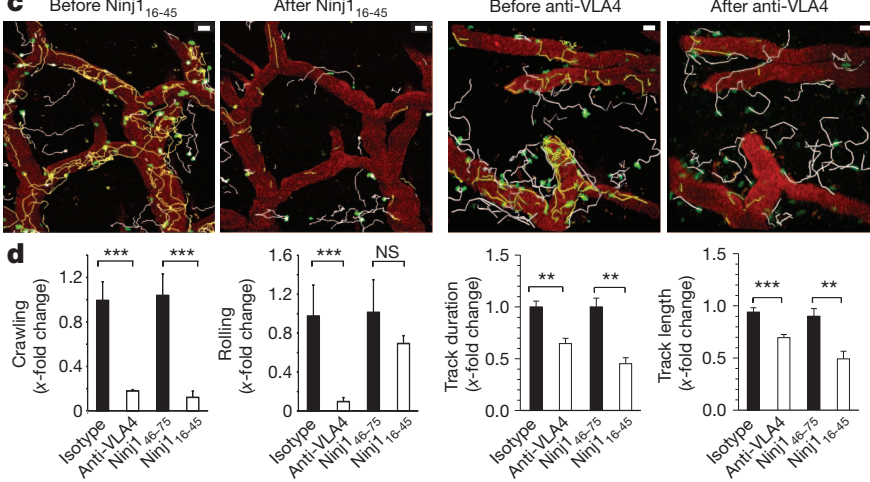

Figure $3 \mid$ Switch of $\mathbf{T}_{\text {blast }}$ cells into a migratory mode. a, Chemotactic reorientation of $\mathrm{T}_{\mathrm{MBP}-\mathrm{GFP}}$ cells during preclinical $\mathrm{EAE}$. $\mathrm{T}_{\mathrm{MBP}-\mathrm{GFP}}$ cells isolated from the indicated organs were assayed for their ability to migrate towards CCL5, CXCL11, CCL19 and CCL21. Cell migration indices (ratio of transmigrated T cells with chemokine versus no chemokine) were calculated by cytofluorometry. Means \pm s.e.m. of four independent experiments. $\mathbf{b}$, Changes of transcript regulations of $\mathrm{T}_{M B P-G F P}$ cells during their activatory $\left(\mathrm{T}_{\text {blast }}\right.$ cells per resting $\mathrm{T}_{\mathrm{MBP}}$ GFP cells) compared to their migratory state (spleen-derived $\mathrm{T}_{\text {migratory }}$ cells per $\mathrm{T}_{\text {blast }}$ cells). Left, scatter plot depicting the upregulated transcripts during activation (green) or migration (red) with a selection of regulated genes. Right, global transcriptional profiles (cluster heat map). Overview of average linkage hierarchical cluster analysis of $\mathrm{T}_{\mathrm{MBP}-\mathrm{GFP}}$ cells in their migratory (first column) or activatory (second column) state and annotated transcripts (rows). Geneexpression changes are depicted by a $\log _{2}$ pseudo-colour scale (ratio of foldchange is indicated). Two prominent clusters are marked by vertical coloured bars. The corresponding gene groups within these clusters are indicated in the boxes. GPCR, G protein-coupled receptor. $\mathbf{c}$, $\mathbf{d}$, Ninj1 as a novel adhesion molecule in $\mathrm{T}_{\text {migratory }}$ cells. $\mathrm{T}$ cell crawling in leptomeningeal vessels is disrupted by Ninj1 or VLA4 blocking (c). $\mathrm{T}_{\text {migratory }}$ cells $60 \mathrm{~h}$ after T-cell transfer were recorded by live two-photon microscopy before or $90 \mathrm{~min}$ after intravenous injection of Ninj1 blocking peptide (amino acids 16-45; Ninj1 $1_{16-45}$ ) or antiVLA4 monoclonal antibodies. Motility tracks ( 30 min recording time) of $\mathrm{T}_{\mathrm{MBP}}$ GFP cells crawling inside the leptomeningeal vessels (yellow tracks). Note that the peptide treatment did not interfere with the motility of extravasated $\mathrm{T}_{\mathrm{MBP}-\mathrm{GFP}}$ cells (white tracks). Scale bars, $20 \mu \mathrm{m}$. Locomotion behaviour of $\mathrm{T}_{\text {migratory }}$ cells after Ninj1 is compared to VLA4 blocking treatment (d). Numbers of intraluminally crawling and rolling $\mathrm{T}_{\text {migratory }}$ cells, track durations and track lengths of individual $\mathrm{T}_{\text {migratory }}$ cells in 30-min intervals were quantified in the leptomenigeal vessels before and 90 min after treatment with PBS, anti-VLA4, blocking Ninj $1_{16-45}$ and Ninj1 control peptide (amino acids $46-75$; Ninj1 $1_{46-75}$ ). Fold changes after the indicated treatment are shown on the $y$ axis. Cumulative data from three independent experiments per treatment. $* P<0.05 ; * * P<0.01$; $* * * P<0.001$. NS, not significant.

downregulated transcripts (out of 30,248 ) for activated compared to migrating $\mathrm{T}_{\mathrm{MBP}-\mathrm{GFP}}$ cells, respectively. These changes ( $\geq 2$-fold) could be grouped into two major gene clusters that included reciprocally 
regulated pathways (Fig. $3 \mathrm{~b}$ ). In comparison to $\mathrm{T}_{\text {blast }}$ cells, $\mathrm{T}_{\text {migratory }}$ cells downregulated their immune activation and proliferation programs (Supplementary Fig. 6a-d); that is, pro-inflammatory cytokines, costimulatory molecules, cell-cycle-associated genes, cyclin-dependent kinases and factors of the DNA replication machinery. By contrast, genes controlling cell motility and cell adhesion were strongly upregulated (Supplementary Fig. 6e). Accordingly, transcription factors that are important for regulating $\mathrm{T}$-cell cycling and migration-for example, Klf2 (ref. 17)-were among the most upregulated genes in $\mathrm{T}_{\text {migratory }}$ cells (Fig. 3b and Supplementary Fig. 6c).

To evaluate the functional relevance of the newly assumed adhesive profile, we tested ninjurin 1 (Ninj1), a two-pass transmembrane adhesion molecule that functions by homophilic binding. Ninj1 was recently found to be expressed in myeloid cells and CNS endothelia, and was upregulated during EAE (Supplementary Fig. $7 \mathrm{a}-\mathrm{c})^{18-20}$. We found Ninj1 expression and a transient upregulation in $\mathrm{T}_{\text {migratory }}$ cells, but not in naïve T or B cells (Supplementary Fig. 7b-d). Intriguingly, intravenous infusion of Ninj1-blocking peptide (amino acids 16-45), that blocks homophilic Ninj1 binding, strongly reduced the numbers of T cells crawling on the intraluminal side of the CNS vessels (Fig. 3c, d, Supplementary Fig. 7e and Supplementary Movie 5). This might explain the reduced $\mathrm{T}_{\text {migratory }}$ cell entry into the CNS and the delayed and ameliorated disease course after intravenous infusion of the Ninj1blocking peptide (Supplementary Fig. 7f, g). Overexpression of Ninj1 by retroviral gene transfer promoted the entry of T cells overexpressing GFP and Ninj1 ( $\mathrm{T}_{\text {MBP-GFP-Ninj1 }}$ cells) into the CNS and accelerated the onset of clinical EAE (Supplementary Fig. $7 \mathrm{~h}-\mathrm{j}$ ). The integrin $\alpha_{4}$ (very late antigen 4, VLA4), whose $\beta 1$ chain was also upregulated in $\mathrm{T}_{\text {migratory }}$ cells (Supplementary Fig. 6e), had similar effects on the intravascular T-cell motility as shown by blockage with VLA4neutralizing antibody (Fig. 3d). It is clear that both adhesion molecules have a role in T-cell crawling by strengthening the endothelial adherence of the cells. Interestingly, Ninj1 blockage was less efficient in interfering with the initial adhesion steps of the cells to the endothelia than the anti-VLA4 treatment (Fig. 3d and Supplementary Fig. 7e).

To explore the regulation dynamics of the migratory mode in $\mathrm{T}_{\mathrm{MBP}}$ GFP cells in vivo, we analysed the expression profiles of a selected set of the regulated genes in T cells during their migratory paths. Our results show that the reprogramming process in T cells is already initiated in the lung, and is continued during their migration through the mediastinal lymph nodes and spleen (Supplementary Fig. 8). Notably, the development of a migratory mode was not restricted to $\mathrm{T}$ cells during transfer EAE: memory or post-activated $\mathrm{T}_{\mathrm{MBP}-\mathrm{GFP}}$ cells after intratracheal or subcutaneous immunizations assumed a very similar migratory mode before they accumulated at the CNS

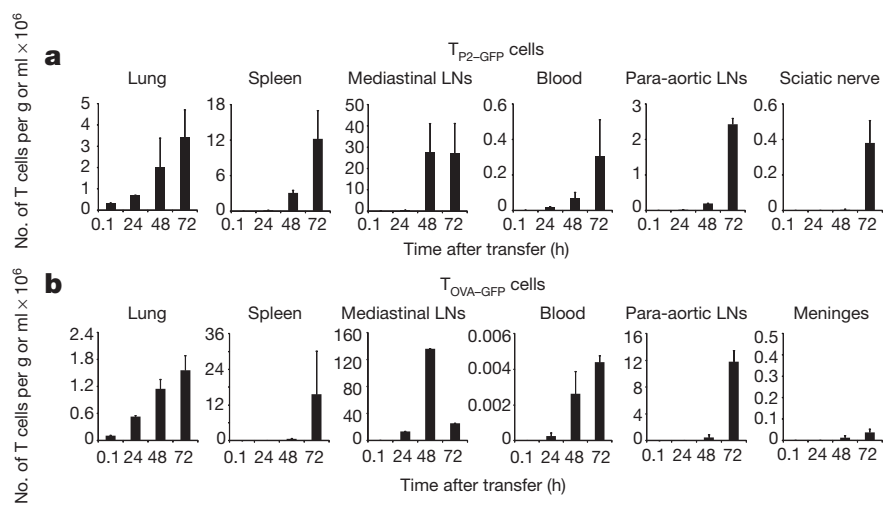

Figure $4 \mid$ Homing into the lung is not limited to encephalitogenic $\mathrm{T}$ cells. a, b. Homing behaviour of neuritogenic $\mathrm{T}_{\mathrm{P} 2-\mathrm{GFP}}$ cells and non-pathogenic $\mathrm{T}_{\text {OVA-GFP }}$ cells resembles that of $\mathrm{T}_{\mathrm{MBP}-\mathrm{GFP}}$ cells. The number of $\mathrm{T}_{\mathrm{P} 2-\mathrm{GFP}}$ cells (a) or $\mathrm{T}_{\text {OVA-GFP }}$ cells (b) in the indicated organs after intravenous transfer. The cells were quantified using cytofluorometry. Means \pm 1 s.d. Representative data of three independent experiments with at least three animals per group.
(Supplementary Fig. 9a-f). Furthermore, the observed homing patterns of intravenously transferred T-cell blasts and their switch to migration-competent effector cells were not restricted to $\mathrm{T}_{\mathrm{MBP}}$ cells, but were also seen in neuritogenic P2-reactive $\mathrm{T}$ cells or $\mathrm{T}$ cells recognizing ovalbumin (Fig. 4 and Supplementary Fig. 9g-k).

Our data show that the preclinical phase of transfer EAE cannot be explained solely by the integrity of the BBB or the immune hostile environment of the CNS having to be breached by activated 'pioneer' $\mathrm{T}$ cells ${ }^{1,2}$ before the mass of the T cells get access into their target organ. The majority of the transferred cells during this phase of transfer EAE home to the peripheral environments of the lung from where they move to the BALT and draining lymph nodes, before they re-enter the blood circulation and finally reach the CNS. On their way, the T cells profoundly reprogram their gene-expression profile, and this includes upregulation of membrane receptors, such as the S1P1, that have a role in guiding the cells out of lymphatic structures ${ }^{21}$. Additionally, the T cells upregulate chemokine receptors and adhesion molecules that regulate their orientation towards inflamed tissues and simultaneously raise their capacity to transgress endothelial barriers, including those of CNS vessels ${ }^{22-24}$. At the same time, the T cells downregulate their proliferation and activation programs and thus prepare for antigen re-encounter and activation. A premature reactivation or hyper-reactivation would cripple the immune response by causing T-cell apoptosis or anergy ${ }^{25,26}$. Importantly, the switch of activated autoaggressive $\mathrm{T}$ cells towards a migratory mode occurs before the onset of any deleterious inflammatory processes within the attacked organs. Several of the genes recently identified in genome-wide association studies as risk genes for the development of multiple sclerosis ${ }^{27}$ were found in the fraction of regulated genes in our transcriptome analysis (Supplementary Fig. 10). Recently, the gut environment came into focus as a potential site for the initial priming of autoreactive $\mathrm{T}$ cells during spontaneous $\mathrm{EAE}^{28}$. We demonstrate here that the lung can serve as a location where autoreactive T cells become reactivated and gain the competence to enter the CNS. It is well known that relapses in multiple sclerosis are triggered by inflammations of the respiratory $\operatorname{tract}^{29}$. The lung is in constant and direct contact with the outer environment and is colonized by microbiota that can actively promote local immune responses ${ }^{30}$. This organ represents a homing place for effector and memory cells relevant to host defence and asthma pathogenesis. At the same time, the lung represents a niche for potentially autoaggressive effector and memory T cells. Our data indicate that stimulatory environmental factors might directly elicit a pathogenic response of these cells.

\section{METHODS SUMMARY}

$\mathrm{CD}^{+} \mathrm{CD}^{-} \alpha \beta \mathrm{TCR}^{+} \mathrm{MBP}-$, ovalbumin- and P2-specific $\mathrm{T}$ cells retrovirally engineered to express enhanced GFP were established from lymph nodes of immunized Lewis rats as reported ${ }^{7}$. All cell lines were tested for cytokine profile, antigen specificity and surface phenotype. Memory animals were established by intraperitoneal transfer of $\mathrm{T}_{\mathrm{MBP}-\mathrm{GFP}}$ cells into neonatal rats. If not otherwise stated, transfer EAE was induced by intravenous injection of $5 \times 10^{6} \mathrm{~T}_{\text {blast }}$ cells or by intratracheal administration of $2 \times 10^{6} \mathrm{~T}_{\text {blast }}$ cells. Active EAE was induced in memory animals by intratracheal or subcutaneous immunization. In naïve animals, aEAE was induced by subcutaneous or intratracheal transfer of resting $\mathrm{T}$ cells followed by immunization. Transfer of migration-competent $\mathrm{T}_{\mathrm{MBP}-\mathrm{GFP}}$ cells into recipient animals, cross-circulation model and therapeutic interference are described in the Methods. Animal experiments were in compliance with regulations of the Bavarian and Lower Saxony state.

Time-lapse two-photon laser-scanning microscopy, fluorescence video microscopy time-lapse recordings and image analyses are described in Methods.

$\mathrm{T}_{\mathrm{MBP}-\mathrm{GFP}}$ cells were isolated from the single organs as described ${ }^{8}$. Cell sorting was carried out using FACS Vantage, FACSAria (Becton Dickinson) or MoFlo (Beckman Coulter). Cytofluorometric analysis was performed with FACS-Calibur operated by Cell Quest software.

Total RNA was used to perform a genome-wide transcriptional profiling assay (Rat Genome 230, Affymetrix). Messenger RNA extraction, complementary DNA reversion and Taqman analyses are described in Methods.

Graphs were generated and statistical tests performed using Graphpad 5.0.4. 
Full Methods and any associated references are available in the online version of the paper.

Received 28 April; accepted 19 June 2012.

Published online 22 August 2012.

1. Wekerle, H. et al. Cellular immune reactivity within the CNS. Trends Neurosci. 9 , 271-277 (1986).

2. Hickey, W. F., Hsu, B. L. \& Kimura, H. T-lymphocyte entry into the central nervous system. J. Neurosci. Res. 28, 254-260 (1991).

3. Brown, D. A. \& Sawchenko, P. E. Time course and distribution of inflammatory and neurodegenerative events suggest structural bases for the pathogenesis of experimental autoimmune encephalomyelitis. J. Comp. Neurol. 502, 236-260 (2007).

4. Kivisäkk, P. et al. Localizing central nervous system immune surveillance: meningeal antigen-presenting cells activate T cells during experimental autoimmune encephalomyelitis. Ann. Neurol. 65, 457-469 (2009).

5. Karin, N. et al. Selective and nonselective stages in homing of T lymphocytes to the central nervous system during experimental allergic encephalomyelitis. J. Immunol. 150, 4116-4124 (1993).

6. Bartholomäus, l. et al. Effector T cell interactions with meningeal vascular structures in nascent autoimmune CNS lesions. Nature 462, 94-98 (2009).

7. Flügel, A. et al. Gene transfer into $\mathrm{CD}^{+}$T lymphocytes: green fluorescent proteinengineered, encephalitogenic $T$ cells illuminate brain autoimmune responses. Nature Med. 5, 843-847 (1999).

8. Flügel, A. et al. Migratory activity and functional changes of green fluorescent effector cells before and during experimental autoimmune encephalomyelitis. Immunity 14, 547-560 (2001).

9. Glabinski, A. R. et al. Central nervous system chemokine mRNA accumulation follows initial leukocyte entry at the onset of acute murine experimental autoimmune encephalomyelitis. Brain Behav. Immun. 9, 315-330 (1995).

10. Kawakami, N. et al. Live imaging of effector cell trafficking and autoantigen recognition within the unfolding autoimmune encephalomyelitis lesion. J. Exp. Med. 201, 1805-1814 (2005)

11. Kawakami, N. et al. The activation status of neuroantigen-specific T cells in the target organ determines the clinical outcome of autoimmune encephalomyelitis. J. Exp. Med. 199, 185-197 (2004).

12. Hogan, R. J. et al. Protection from respiratory virus infections can be mediated by antigen-specific CD4(+) T cells that persist in the lungs. J. Exp. Med. 193, 981-986 (2001).

13. Lo, J. C. etal. Differential regulation of CCL21 in lymphoid/nonlymphoid tissues for effectively attracting T cells to peripheral tissues. J. Clin. Invest. 112, 1495-1505 (2003).

14. Pham, T. H. et al. S1P1 receptor signaling overrides retention mediated by $\mathrm{G}$ alpha i-coupled receptors to promote T cell egress. Immunity 28, 122-133 (2008).

15. Asperti-Boursin, F. et al. CCR7 ligands control basal T cell motility within lymph node slices in a phosphoinositide 3-kinase-independent manner. J. Exp. Med. 204, 1167-1179 (2007)

16. Brinkmann, V. et al. Fingolimod (FTY720): discovery and development of an oral drug to treat multiple sclerosis. Nature Rev. Drug Discov. 9, 883-897 (2010).

17. Carlson, C. M. et al. Kruppel-like factor 2 regulates thymocyte and T-cell migration. Nature 442, 299-302 (2006).

18. Ahn, B. J. et al. Ninjurin1 is expressed in myeloid cells and mediates endothelium adhesion in the brains of EAE rats. Biochem. Biophys. Res. Commun. 387, 321-325 (2009).

19. Araki, T. \& Milbrandt, J. Ninjurin, a novel adhesion molecule, is induced by nerve injury and promotes axonal growth. Neuron 17,353-361 (1996).

20. Ifergan, I. et al. Role of Ninjurin-1 in the migration of myeloid cells to central nervous system inflammatory lesions. Ann. Neurol. 70, 751-763 (2011)
21. Matloubian, M. et al. Lymphocyte egress from thymus and peripheral lymphoid organs is dependent on S1P receptor 1. Nature 427, 355-360 (2004).

22. Yednock, T. A. et al. Prevention of experimental autoimmune encephalomyelitis by antibodies against alpha 4 beta 1 integrin. Nature 356, 63-66 (1992).

23. Sporici, R. \& Issekutz, T. B. CXCR3 blockade inhibits T-cell migration into the CNS during EAE and prevents development of adoptively transferred, but not actively induced, disease. Eur. J. Immunol. 40, 2751-2761 (2010).

24. Zheng, H. M. et al. Mimic peptides bonding specifically with the first and second extracellular loops of the $\mathrm{CC}$ chemokine receptor 5 derived from a phage display peptide library are potent inhibitors of experimental autoimmune encephalomyelitis. Inflamm. Res. 60, 759-767 (2011).

25. Lenardo, M. J. Interleukin-2 programs mouse alpha beta T lymphocytes for apoptosis. Nature 353, 858-861 (1991).

26. Tham, E. L., Shrikant, P. \& Mescher, M. F. Activation-induced nonresponsiveness: a Th-dependent regulatory checkpoint in the CTL response. J. Immunol. 168, 1190-1197 (2002)

27. Sawcer, S. et al. Genetic risk and a primary role for cell-mediated immune mechanisms in multiple sclerosis. Nature 476, 214-219 (2011).

28. Berer, K. etal. Commensal microbiota and myelin autoantigen cooperate to trigger autoimmune demyelination. Nature 479, 538-541 (2011).

29. Sibley, W. A., Bamford, C. R. \& Clark, K. Clinical viral infections and multiple sclerosis. Lancet 325, 1313-1315 (1985).

30. Ichinohe, T. et al. Microbiota regulates immune defense against respiratory tract influenza A virus infection. Proc. Natl Acad. Sci. USA 108, 5354-5359 (2011).

Supplementary Information is linked to the online version of the paper at www.nature.com/nature.

Acknowledgements The authors thank A. Stas, S. Hamann, N. Meyer and I. Haarmann for technical assistance. N. Plesnila supported this work with advice in surgical preparations; T. Issekutz provided anti-CXCR3 and anti-VLA4 monoclonal antibodies. We are grateful to D. Johnson and F. Lühder for critical reading of the manuscript. We thank W. Leibold for critical discussions. We thank C. Ludwig for text editing. Hartmut Wekerle is Senior Research Professor of the Hertie Foundation. This work was supported by the Deutsche Forschungsgemeinschaft (TRR-SFB43, FORR 1336), the Bundesministerium für Bildung und Forschung ('UNDERSTAND MS') and the Hertie Foundation (grant 1.01.1/11/004)

Author Contributions F.O. and K.S. carried out most of the cell transfer, EAE studies, cytofluorometric characterizations and cell-transfer experiments. C.S. together with F.O. performed the lung-migration studies. V.K.U. contributed by analysing the gene transcriptome data. C.Sch. contributed to the generation of imaging data and the treatment with anti-CXCR3 monoclonal antibody. D.L. and M.N. contributed with characterizations of the migratory T cells. K.H. coordinated the cell sampling for the transcriptome analyses. W.N. and H.L. contributed by carrying out the transcriptome analyses. C.L., R.S. and M.V. helped with the statistical transcriptome data analysis. V.B. provided FTY720 and gave advice about its experimental handling. W.E.F.K. and J.E. performed cell sorting. H.W. contributed with scientific advice and contributed to the design of the transcriptome analysis. C.F.-K. contributed to the morphological studies of the lung tissue. A.F. and F.O. designed the study, coordinated the experimental work and wrote the manuscript with input from co-authors.

Author Information The data discussed in this publication have been deposited in the National Center for Biotechnology Information (NCBI) Gene Expression Omnibus and are accessible through GEO Series accession number GSE38645 (http:// www.ncbi.nlm.nih.gov/geo/query/acc.cgi?acc=GSE38645). Reprints and permissions information is available at www.nature.com/reprints. The authors declare no competing financial interests. Readers are welcome to comment on the online version of the paper. Correspondence and requests for materials should be addressed to A.F. (fluegel@med.uni-goettingen.de). 


\section{METHODS}

Animals. Rats on a Lewis (LEW/Crl) genetic background were bred by the animal facilities of the Max Planck Institute for Biochemistry and the University Medical Center Göttingen. All animal experiments were performed according to the Bavarian and Lower Saxony state regulations for animal experimentation and were approved by the responsible authorities (numbers 209.1/211-2531-36/04 and 33.11.42502-04-016/09, respectively).

Antigens. T-cell clones were specific for guinea-pig MBP, ovalbumin (OVA) and P2 peptide. MBP was isolated from guinea-pig brains as described ${ }^{31}$. OVA was from Sigma. The synthetic peptide of bovine P2 myelin protein (amino acids 53 78) was synthesized by the Max Planck Institute for Biochemistry.

Generation and culturing of $\mathrm{T}$ cells. MBP-, OVA- and $\mathrm{P} 2 \mathrm{CD}^{+}{ }^{+} \mathrm{T}$ cells retrovirally engineered to express the enhanced GFPs (eGFPs) ( $\mathrm{T}_{\mathrm{MBP}-\mathrm{GFP}}$ $\mathrm{T}_{\mathrm{OVA-GFP}}, \mathrm{T}_{\mathrm{P} 2-\mathrm{GFP}}$ ) were generated as reported ${ }^{7}$. Ten days after subcutaneous immunization with MBP, OVA, P2 peptide in CFA (which was prepared by supplementing Incomplete Freund's Adjuvant (Difco Laboratories) with $2 \mathrm{mg}$ $\mathrm{ml}^{-1}$ of inactivated Mycobacterium tuberculosis H37Ra (Difco Laboratories)), cells were collected from the draining lymph nodes and co-cultured in the presence of retrovirus-producing GP+E 86 packaging cells. Murine stem-cell virus (pMSCV, Invitrogen) in which the eGFP gene (Invitrogen) had been integrated (pMSCV-eGFP) was used as the retroviral vector. After 2 days of co-culture, T-lymphocyte blasts were expanded in IL-2-containing growth medium for 5 days and then re-stimulated in the presence of irradiated thymocytes pulsed with the specific antigen. Selection with G418 and amplification of the T cells was carried out as reported ${ }^{32}$. All the cell lines were $\mathrm{CD} 4^{+}, \mathrm{CD}^{-}$and $\alpha \beta \mathrm{TCR}^{+}$, and were extensively tested for their phenotype, cytokine profile and antigen specificity.

Memory animals were prepared as previously described ${ }^{33}$. Briefly, $\mathrm{T}_{\mathrm{MBP}-\mathrm{GFP}}$ cells $\left(2 \times 10^{6}\right.$ cells per animal; 4 days after MBP stimulation) were transferred intraperitoneally into neonatal rats within $48 \mathrm{~h}$ post partum. The transferred cells (memory $\mathrm{T}_{\mathrm{MBP}-\mathrm{GFP}}$ cells; $\mathrm{CD}^{+} \mathrm{CD}^{-}$) persisted lifelong within the immune repertoire of the animals maintaining a memory phenotype (L-selectin ${ }^{\text {low }}$ and CD45RC low, CD $\left.44^{\text {high }}\right)$. Experiments were performed in animals that were 10 14 weeks old.

EAE models. For transfer, MBP-specific $\mathrm{T}_{\mathrm{GFP}}$ cells were stimulated as described above. Two days later, naïve Lewis rats (6-8 weeks old) received tail-vein injections of $5 \times 10^{6} \mathrm{~T}_{\mathrm{MBP}-\mathrm{GFP}}, \mathrm{T}_{\mathrm{P} 2-\mathrm{GFP}}$ or $\mathrm{T}_{\text {OVA-GFP }}$ blasts ( $\mathrm{T}_{\text {blast }}$ cells). Alternatively, $2 \times 10^{6}$ (in $100 \mu \mathrm{l}$ Eagle's Hepes (EH) medium) $\mathrm{T}_{\text {blast }}$ cells were injected intratracheally into naïve animals previously anaesthetized and intubated. For transfer of migration-competent $\mathrm{T}_{\mathrm{MBP}-\mathrm{GFP}}$ cells, $3 \times 10^{6} \mathrm{~T}_{\text {migratory }}$ cells were isolated from the spleen $60 \mathrm{~h}$ after T-cell transfer and $1 \times 10^{6}$ from the lung $48 \mathrm{~h}$ after T-cell transfer and immediately transferred intravenously into recipient animals.

Active EAE was induced in naive or memory animals by intratracheal or subcutaneous immunization.

For intratracheally induced EAE, $3 \times 10^{6}$ resting $\mathrm{T}_{\mathrm{MBP}-\mathrm{GFP}}$ cells were intratracheally transferred into anaesthetized and intubated naïve animals. $3 \mathrm{~h}$ later the rats were immunized by intratracheal instillation of an emulsion (50 $\mu$ in PBS) containing CFA $\left(20 \mu \mathrm{l}\right.$ per animal), MBP $\left(1 \mathrm{mg} \mathrm{ml}^{-1}, 12.5 \mu \mathrm{l}\right.$ per animal) and China ink (1\%). China ink could be detected both macroscopically and microscopically, confirming the correct intrapulmonary distribution of the antigen. The procedure was tolerated well. Note that administration of China ink alone, MBP in China ink, or OVA in CFA and China ink did not induce any clinical effect.

For subcutaneously induced active EAE, $1.5 \times 10^{6} \mathrm{~T}_{\mathrm{MBP}-\mathrm{GFP}}$ cells were injected into the foot pad of naive animals. $12 \mathrm{~h}$ later the animals were immunized by subcutaneous injection of an emulsion containing CFA ( $35 \mu \mathrm{l})$ and MBP $\left(1 \mathrm{mg} \mathrm{ml}^{-1}, 35 \mu \mathrm{l}\right)$.

The same intratracheal or subcutaneous immunization protocols were applied to induce active EAE in memory animals.

The animals were observed daily for clinical symptoms. Their disease stage was scored as follows: 0 , no disease; 1 , flaccid tail; 2 , gait impairments; 3 , complete hind-limb paralysis; 4, tetraparesis; and 5, dead.

Pre-activation of the BBB. BBB priming was induced by transfer of $5 \times 10^{6}$ nonlabelled $\mathrm{T}_{\text {blast }}$ cells. Alternatively, $150 \mathrm{ng}$ of LPS ( $25 \mu \mathrm{l}$ of volume (LPS from Escherichia coli 0127:B8 Sigma-Aldrich)) were stereotactically injected into the cisterna magna of anaesthetized animals.

Two-photon laser-scanning microscopy equipment. Two-photon laserscanning microscopy was carried out using a Zeiss Laser Scanning Microscope 710 combined with a Coherent Chameleon Vision II laser system. The excitation wavelength was set to $880 \mathrm{~nm}$ and the pulsed laser was routed through a Zeiss $\times 20$ water immersion objective (NA 0.95). Fluorescent signals were detected using non-descanned detectors equipped with 525/50-nm and 630/69-nm band-pass filters (Semrock).

Surgical procedure and intravital imaging settings. Animals were anaesthetized using Ketamin (10\%, Medistar) and Xylazin (Xylariem $20 \mathrm{mg}$, Riemser
Arzneimittel) in equal proportions ( $100 \mu \mathrm{l}$ per $100 \mathrm{~g})$, tracheally intubated and ventilated with $1.5-2 \%$ isoflurane. A spinal cord imaging window was established at the level of Th12/L1 as previously described ${ }^{6,34}$. Animals were stabilized in a custom-made microscope stage. Body temperature was controlled by a heated pad $\left(37^{\circ} \mathrm{C}\right)$. Vital parameters were monitored during the imaging. Blood vessels were labelled by intravenous infusion of fluorescent dextran (Invitrogen).

Acute slicing and imaging settings. Acute spinal-cord slices were prepared as reported ${ }^{10}$, with minor modifications. In brief, spinal cords were explanted and embedded in 7\% low-melting agarose (Carl Roth GMBH). Acute slices (thickness of $300 \mu \mathrm{m}$ ) were prepared using a Vibrotome (Campden Vibroslicer).

Acute lung-slice preparation was adapted from a protocol described previously $^{35}$. In brief, the lung was inflated with $2 \%$ low-melting agarose through the trachea. Subsequently, the lung was cut into pieces and embedded in $7 \%$ agarose gel. After hardening, slices of $1 \mathrm{~mm}$ in thickness were obtained using a Vibratome. Acute spinal-cord and lung slices were stored on ice in buffered cell medium and constantly oxygenized with carbogen until image acquisition. All the procedures were performed at $4{ }^{\circ} \mathrm{C}$

A custom-made heating chamber was supplied with humidified carbogen to visualize T-cell movement in acute slices of lung or spinal cord. Highresolution overview images were acquired using the Zeiss tile-scan module; time-lapse videos were acquired in 60-s intervals with approximately three spots imaged in parallel.

Image analysis after intravital imaging. Three-dimensional reconstructions were generated using Imaris 7.1.1 (Bitplane). To determine T-cell velocity, fourdimensional data were generated by the Imaris Track module and revised manually. Motility parameters and trajectories were calculated from the obtained position coordinates using Excel (Microsoft). Crawling and rolling cells were defined as reported previously ${ }^{2}$.

Analysis of acute lung-slice overview images. Files were exported from the ZEN 2009 Software and analysed in ImageJ 1.45d (National Institutes of Health) Shading correction was carried out using Photoshop CS5 (Adobe Systems). For two-photon images with China-ink traces, a white-noise reduction was performed by removing signals present across all channels on a single-plane basis using ImageJ. For quantitative analysis, the green-channel image was enhanced by subtraction of autofluorescent, overlapping signals from the red and blue channels combined with noise reduction using ImageJ.

To quantify bronchiolar association of $\mathrm{T}$ cells in ImageJ, regions of transversally cut bronchiolar structures were subdivided into a peribronchial region (as determined by high collagen density) and a closely associated parenchymal region, defined as a $200-\mu \mathrm{m}$ band surrounding, but not including, the peribronchial region. Mean pixel intensities (that is, the sum of all pixel values in the selection divided by the number of selected pixels) in these two regions were determined in the enhanced green-channel image and their ratio was defined as a measure for bronchiolar cell accumulation (bronchiolar association index). A non-parametric statistical analysis was performed (Dunn's multiple comparison test) using Graphpad 5.0.4 (GraphPad Software).

Overall cell counts per overview image were assessed by Imagej's particle analyser after watershed segmentation of the enhanced green-channel image. Cell numbers from peribronchial accumulations were normalized to the relative frequency of bronchioles per analysed region to account for fluctuations in bronchiole density across multiple slices.

Analysis of acute lung-slice time-lapse videos. Three-dimensional reconstructions were created as described above. If the blue channel signal from the timelapse data was too dim for high-quality three-dimensional reconstruction, high-resolution snap-shot acquisitions of the same area were overlaid on the time-lapse videos to provide a detailed view of the T-cell movement in the pulmonary environment.

Fluorescence-microscopy equipment and imaging set-up. A Zeiss Axio Observer Fluorescence Microscope was used in combination with an HXP120C illuminator routed through a Zeiss Plan Apochromat $\times 10$ Air Objective. Fluorescent signals were detected using a Zeiss AxioCam HSM video camera. An atmosphere suitable for live imaging was generated by a Zeiss Heating Unit $\mathrm{XL}$ with constant carbogen gas supply. Glass-bottom wells (Greiner Bio-One) with custom-made compartments were used to acquire images from two treatment groups simultaneously. Multi-spot time-lapse videos were acquired with 200-ms image acquisition for the green (excitation: $470 \mathrm{~nm}$, emission: $509 \mathrm{~nm}$ ) and red (excitation: $558 \mathrm{~nm}$, emission: $583 \mathrm{~nm}$ ) channels and approximately 30-ms image acquisition for brightfield. Time-lapse image series were acquired (1-min intervals) with multiple spots in parallel.

Analysis of time-lapse videos. All videos were analysed using Imaris 7.1.1. Cell trajectories were determined using the tracking module and revised manually. All 60 -frame videos ( $1 \mathrm{~min}$ per frame, $60 \mathrm{~min}$ per video) were split into subsets of 10 frames for analysis. The relevant statistical data (for example, track speed) were 
exported to Microsoft Excel for further analysis. Cells that were visible in more than 3 of the 10 frames were included in the analysis. A cell was defined as motile if it moved more than $10 \mu \mathrm{m}$ away from its origin during the 10 -frame interval. For quantification of cell velocities, only motile cells were considered. Graphs were generated and statistical tests performed using Graphpad 5.0.4.

Cell isolation, cytofluorometry and fluorescence-activated sorting. $\mathrm{T}_{\mathrm{MBP}-\mathrm{GFP}}$ cells were isolated from spleen, blood, meninges and CNS parenchyma, as described previously ${ }^{6,8,34}$. From lymph nodes, $\mathrm{T}_{\mathrm{MBP}-\mathrm{GFP}}$ cells were retrieved by sieved homogenization. Bone-marrow $\mathrm{T}_{\mathrm{MBP}-\mathrm{GFP}}$ cells were isolated by flushing the cavity of the femur. To recover $\mathrm{T}_{\mathrm{MBP}-\mathrm{GFP}}$ cells from lung, the organ was mechanically minced (McIlwain Tissue Chopper) and incubated with $0.3 \%$ collagenase (Sigma-Aldrich) for $1 \mathrm{~h}$ at $37^{\circ} \mathrm{C}$ under constant shaking. Subsequently, the tissue was forced through a metal mesh and washed in $\mathrm{EH}$ medium. T cells were isolated by percoll gradient. Immediately after cell preparation, $\mathrm{T}_{\mathrm{GFP}}$ cells were sorted using a FACS Vantage or a FacsAria cell sorter (both by Becton Dickinson) or MoFlo (Beckman Coulter). All procedures were performed at $4{ }^{\circ} \mathrm{C}$. Cytofluorometric analysis was carried out with a FACS-Calibur operated by Cell Quest software (Becton Dickinson). The number of $\mathrm{T}_{\mathrm{MBP}-\mathrm{GFP}}$ cells was determined in relation to a known absolute number of added phycoerythrinlabelled beads (Becton Dickinson). For surface staining the following antibodies

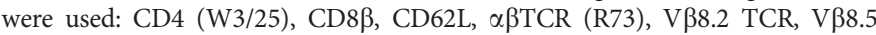
TCR, V $\beta 10$ TCR, V $\beta 16$ TCR, V $\alpha 4$ TCR, V $\alpha 8$ TCR, CD45RA (OX33), CD11b (OX42), CD25 (OX39), CD134 (OX40), transferrin receptor (CD71), basigin (CD147), ItgB1(CD29) and neuropilin (Santa Cruz). Mouse immunoglobulin-

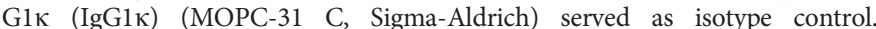
Allophycocyanin (APC)-labelled anti-mouse antibody (Dianova) was used as the secondary antibody. All antibodies were purchased from Serotec unless stated otherwise. Intracellular staining for IFN- $\gamma$ and IL-17 was carried out as described ${ }^{6}$. For intracellular staining of Ninj1, KLF2 and KLF4, samples were fixed in paraformaldehyde (PFA; 2\%) for 20 min, permeabilized by Cytofix-Cytoperm buffer (Becton Dickinson) and then incubated with anti-Ninj1 monoclonal antibodies (MABs) (Becton Dickinson), anti-KLF2 (Chemicon international) and anti-KLF4 antibodies (Affinity Bioreagents) for $45 \mathrm{~min}$. APC-labelled anti-mouse antibody and APC-labelled anti-rabbit antibody (both from Dianova) were used as secondary antibodies for Ninj1, and KLF2 and KLF4, respectively.

In vivo proliferation and cell cycle analysis. 5-bromodeoxyuridine (BrdU) (120 $\mathrm{mg} \mathrm{kg}^{-1}$ body weight; Becton Dickinson) was injected intraperitoneally $2 \mathrm{~h}$ before organ recovery. BrdU-containing $\mathrm{T}_{\mathrm{MBP}-\mathrm{GFP}}$ cells were isolated from the single tissues and stained using a BrdU Flow kit (Becton Dickinson) according to the manufacturer's instructions. Cells were re-suspended in 7-amino-actinomycin $\mathrm{D}$ (7-AAD) solution just before flow-cytometry analyses.

Cross-circulation model. Diethlyether anaesthesia followed by subcutaneous atropine $\left(0.5 \mathrm{mg} \mathrm{kg}^{-1}\right)$ injection was induced in a naive animal that was not pre-treated and in an animal that had received $5 \times 10^{6} \mathrm{~T}_{\text {MBP-GFP }}$ cells $60 \mathrm{~h}$ beforehand (pre-EAE). Animals were then intubated and ventilated with $0.8 \%$ halothane in $70 \% \mathrm{~N}_{2} \mathrm{O}$ and $30 \% \mathrm{O}_{2}$. A rectal probe was used to monitor body temperature. Body temperature was controlled by a heated pad $\left(37^{\circ} \mathrm{C}\right)$. The tail artery cannulation was used to measure the mean arterial blood pressure and for blood sampling at regular intervals to determine $\mathrm{pH}$ and arterial blood gases. A cannula was introduced into the tail artery in a proximal direction. Distal to the cannula, the artery was ligated and a second cannula was introduced in the distal direction of the tail artery. The two animals were connected through a heparinized catheter (Harvard Apparatus) from the proximal to the distal part and vice versa. A constant blood flow between the two animals was regularly monitored by injection of a small amount of $\mathrm{NaCl}$. The arterial connection lasted 8 to $12 \mathrm{~h}$. Thereafter, the animals were killed and the numbers of $\mathrm{T}_{\mathrm{MBP}-\mathrm{GFP}}$ cells in the spleen and CNS of pre-EAE animals and animals that were not pre-treated were quantified by flow cytometry after the 12-h anastomosis. The efficiency of distributions across the blood shunt was measured in each experiment; as the 'transfer rates' substantially fluctuated between the different animal pairs (probably owing to variable blood flows within the shunts) relative numbers were given.

Microarray analysis. Activated $\mathrm{T}$ cells ( $\mathrm{T}_{\mathrm{MBP}-\mathrm{GFP}}$ blast cells) were obtained 2 days post re-stimulation in vitro using thymocytes and MBP antigen followed by FACS sorting. Resting $\mathrm{T}$ cells $\left(\mathrm{T}_{\mathrm{MBP}-\mathrm{GFP}}\right.$ resting cells) were obtained 7 days post antigen exposure followed by FACS sorting. FACS sorting of spleen-derived migratory $\mathrm{T}$ cells ( $\mathrm{T}_{\mathrm{MBP}-\mathrm{GFP}}$ migratory cells) was performed 3 days post transfer. The sorting reached over $95 \%$ of purity. Transfer EAE was induced as described above. Cells were collected in cold PBS containing 1\% rat serum, re-suspended in lysis buffer containing $\beta$-mercaptoethanol and mechanically broken up with a $23 \mathrm{G}$ needle. RNA was isolated from $T_{M B P-G F P}$ blast cells, $T_{M B P-G F P}$ resting cells and $T_{M B P-G F P}$ migratory cells using the Qiagen RNeasy mini kit. For every RNA sample, more than $10 \times 10^{6}$ cells were used. RNAs from four to six independent experiments with four animals in each experiment were combined into one RNA sample. Two
RNA samples from spleen, five samples from $\mathrm{T}_{\mathrm{MBP}-\mathrm{GFP}}$ blast cells and four from $\mathrm{T}_{\mathrm{MBP}-\mathrm{GFP}}$ resting cells were analysed further. Integrity, size range and concentration of the RNAs were evaluated using the Agilent Bioanalyser (Agilent Technologies) and agarose gel electrophoresis. Total RNA was reverted into biotinylated cRNA according to the manufacturer's protocol (Affymetrix); the resultant cRNA was fragmented and then hybridized to the GeneChip Rat Genome 230Array (Affymetrix). The arrays were washed, stained and scanned by the GeneChip System confocal scanner (Hewlett Packard). Gene-expression profiles were background corrected and normalized on probe level using the variance stabilization method described previously ${ }^{36}$. Normalized probe intensities were summarized into gene-expression levels using the additive model as described ${ }^{37}$ Comparison analysis was performed on the gene-expression data set pertaining to $\mathrm{T}_{\mathrm{MBP}-\mathrm{GFP}}$ blast cells, $\mathrm{T}_{\mathrm{MBP}-\mathrm{GFP}}$ resting cells and $\mathrm{T}_{\mathrm{MBP}-\mathrm{GFP}}$ migratory cells, to obtain transcriptomes of activated state $\left(\mathrm{T}_{\text {blast }}\right.$ versus $\left.\mathrm{T}_{\text {resting }}\right)$ and migratory state ( $\mathrm{T}_{\text {migratory }}$ versus $\left.\mathrm{T}_{\text {blast }}\right)$. Transcriptomes were compared using Matlab. Average linkage hierarchical cluster analysis was performed on the annotated expression data set using Genesis ${ }^{38}$. Pathway-based analysis was carried out using GenMAPP $^{39}$. For Gene-ontology based analysis, recent annotations for affymetrix probesets were downloaded from the Gene Ontology consortium database.

Quantitative PCR. Total RNA was isolated using the standard Trizol method. cDNA was synthesized using Superscript III reverse transcriptase (Invitrogen). Quantitative PCR analysis was carried out using the 7500 Real Time PCR system (PE Applied Biosystems), as described ${ }^{8,34,40}$. $\beta$-actin was used as the house-keeping gene. Data were obtained by independent duplicate measurements. The CT value of the individual measurements did not exceed 0.5 amplification cycles. Several rat primers and probes were recently described ${ }^{6,34}$.

The primer probes not previously reported are: $\mathrm{Ccr} 7$; forward, 5'-GTGTAGT CCACGGTGGTGTTCTC-3' ; backward, 5' -CTGGTCATTTTCCAGGTGTGCT-3'; probe, 5' -CCGATGTAGTCGTCTGTGA-3'. Ccl21; forward, 5'-TCCTTAGCT TGGTCCTGGTTCT-3'; backward, 5'-GAATCTTCTTCTGGCTGTACCTAA GAC-3'; probe, 5'-CCCGTGGACCCAAGGCAGTGAC-3'. Ninj1; forward, 5'-GGGCTGGTTTTCATCATCGT-3' ; backward, 5' -GGTGCCACGTCCATGA CA-3'; probe, 5'-ACATCTTCATTACGGCCTTTGGAGTCCAG-3'. Rhamm; forward, 5'-GCGCAGACTCTGAGAGATGTT-3'; backward, 5' - GCCATGGC TACTTTTTCTTG-3'; probe, 5'-CTCAGTTAGAAAGCTATAAGTCATC-3' Txk; forward, 5' -ACCTGGAGAAGAGCTGCTATATC-3'; backward, 5' -TCT TTACTACGCAGGCAGAACT-3'; probe, 5' -CAGGGATCTGGCTGCCAGGA ACTG-3'. Klf4; forward, 5'-CAGTCGCAAGTCCCCTCTCT-3'; backward 5'-TATCAAGAGCTCATGCCAC-3'; probe, 5'-CTCTTTGGCTTGGGCTCCT-3' Zfp36l1; forward, 5'-CACGACACAACAGATCCTAGTCCTT-3'; backward, 5'-GAGCATCTTGTTACCCTTGCATAA-3' ; probe, $5^{\prime}$-CCCCGTGCGAACGC CCAC- $3^{\prime}$. $I l 7 r$; forward, 5' -AATGCCCAGGATGGAGATCTAGA-3'; backward, 5'-TGAGTGCTGATTTCCATCCACTT-3'; probe, 5' -ATGATCACTCCTTCT GGTGCCACAGCC-3'. Tnfrsf14; forward, 5'-CTGTCCCCCACAGACCTATA CC-3'; backward, 5' -CAGGCCCATGTCTGGATCAC-3'; probe, 5' -CCCATG CGAATGGCCTGAGCAA-3'. $M y c$; forward, 5'-CCCCTAGTGCTGCATGAA GAG-3'; backward, 5' -TCCACAGACACCACATCAATTTC-3'; probe, 5' -CA CCACCAGCAGCGACTCTGAAGAAG-3' . Batf; forward, 5' -GACAGCAGCGA CTCCAGCTT-3'; backward, 5' -TCTCTCCTCTGAACTTTCCTCACA-3'; probe, 5'-CCCCGGCAAGCAGGACTCATCC-3'. Plek; forward, 5'-CACGGA CTGGGAAATGAGGATA-3'; backward, 5'-TCCTCTCTATTTTCCTAGTT GTAGACTCTTGCA-3'; probe, 5'-AGAAGCATTGACGCGAATCCGACT-3' $R g s 1$; forward, 5'-CAGATGCTGTGAAACAAATCAATATTG-3'; backward, 5'-CGTATATGACTTTTTGTGCTTCATCAA-3'; probe, 5' -TCGACAGCCA AGAAGATCAAAACACCAACT-3' . Arl6ip4; forward, 5' -CTCTGGATCAGTG GCACAGATC-3'; backward, 5' -CATGGCCTGGATACGAGACTTC-3'; probe 5' -TGGCCCAGTCCTGACAGACGAGC-3' . For all TaqMan probes, a combination of $5^{\prime}$-FAM and $3^{\prime}$-TAMRA quencher was used.

Histology. Histological analysis was performed as described previously ${ }^{8}$. In brief, animals were perfused with $4 \%$ paraformaldehyde in PBS. The single organs were then post-fixed in the same buffer for $48 \mathrm{~h}$ at $4{ }^{\circ} \mathrm{C}$. After a $24-\mathrm{h}$ incubation period in $30 \%$ sucrose in PBS, the organs were embedded in Tissue Tek O.C.T Compound (Sakura Finetek), frozen and cut transversally into slices of $15-\mu \mathrm{m}$ thickness using a Leica CM305S cryostat (Leica Microsystems) at $-20^{\circ} \mathrm{C}$. Images of the slices were acquired using a Zeiss Axio Observer Fluorescence Microscope. Full-body cut preparation was accomplished as previously described ${ }^{41}$. In brief, after the perfusion and postfixation steps, de-calcification was performed by incubating the total body in $14 \%$ EDTA for 2 weeks. Several tiles were assembled using the photomerge function in Adobe Photoshop CS5.

Chemotactic assays. Directional migration of effector T cells was evaluated using 96-well trans-well plates (Corning Costar, $5-\mu \mathrm{m}$ pore size) as described previously ${ }^{40}$. Briefly, $1 \times 10^{5} \mathrm{~T}_{\mathrm{GFP}}$ cells ex vivo isolated or obtained from in vitro culture were loaded in the upper chamber. CCL5 $\left(0.1 \mathrm{ng} \mathrm{ml}^{-1}\right.$, Serotec), CXCL-11 
(0.1 $\left.\mathrm{ng} \mathrm{ml}^{-1}, \mathrm{R} \& \mathrm{D}\right)$, CCL19 and CCL21 (both $0.1 \mathrm{ng} \mathrm{ml}^{-1}$, Peprotech), or no chemokines were added to the lower chamber. The plates were incubated for $4 \mathrm{~h}$ at $37^{\circ} \mathrm{C}$. The number of effector T cells that had migrated through the membrane was counted by flow cytometry and quantified as a percentage of the input. Antibody and peptide treatments. Hamster anti-rat CXCR3 blocking antibody (clone XR3.2, provided by T. Issekutz) was administered intravenously at $4 \mathrm{mg}$ $\mathrm{kg}^{-1}$ daily for the entire EAE course as described previously ${ }^{23}$. Ninj1 $1_{16-45}$ (PGSP GSPD ASPP RW GL RNRP INV NHYA NKK) or Ninj1 $1_{46-75}$ (SAAE SMLD IALL MANA SQLK AVVE QGNEFA) were synthesized from the peptide service of the Charité as described previously ${ }^{42}$. Anti-CD49d (integrin $\alpha_{4}$, anti-VLA4, clone TA-2) antibodies were provided by T. Issekutz. For the motility studies, the peptides or the VLA4 MABs (both $1 \mathrm{mg} \mathrm{kg}^{-1}$ ) were infused intravenously during intravital imaging. For the EAE studies, Ninj1 peptides or VLA4 MABs were administered intravenously at $1 \mathrm{mg} \mathrm{kg}^{-1}$, starting $36 \mathrm{~h}$ after T-cell transfer, either three times or once per day, respectively.

Separation of bronchial and alveolar tissue. Lungs of naïve rats were inflated with low-melting agarose as described above. Slices were prepared and stained briefly with methyl blue. Using a Leica-wildM3Z stereomicroscope, bronchiolar or alveolar structures were prepared and transferred into lysis buffer (Qiagen RNeasy mini kit) at $4{ }^{\circ} \mathrm{C}$. Tissue pieces were solubilized using a dounce homogenizer and RNA was processed as described for quantitative PCR.

PTX pre-treatment of $\mathrm{T}$ cells. $\mathrm{T}_{\mathrm{MBP}-\mathrm{GFP}}$ blast cells (2 days after re-stimulation) were cultured for $1 \mathrm{~h}$ in the presence of $100 \mathrm{ng} \mathrm{ml}^{-1}$ of PTX (List Biological Laboratories) or its B subunit (Calbiochem). These cells were used for transfer EAE. The chosen dose of PTX was able to block CXCL11- and CCL5-mediated trans-well transmigration of in-vitro- and ex-vivo-isolated $\mathrm{T}_{\mathrm{MBP}-\mathrm{GFP}}$ cells.

FTY720 treatment. Rats were treated orally with FTY720 (PKF116-812-AA-2, Novartis Pharma) at $1 \mathrm{mg} \mathrm{kg}^{-1}$ body weight by gavage, as described ${ }^{43,44}$. Treatment was started 1 day before T-cell transfer and was applied daily. EAE was induced as described above by the transfer of $\mathrm{T}$ cells.

Overexpression of Ninj1 in effector T cells. Rattus norvegicus ninjurin $1 \mathrm{cDNA}$ (NM_012867, 459 bp) was amplified by PCR using cDNA of effector T cells and the following primers: forward, 5' -ATGGATCCCGGCACCGAGGAGTACG-3', backward, 5'-CTACTGCCGGGGTGCCACGTCCA-3' and subsequently cloned in the pGEM-T easy Vector System (Promega). The EcoR1-EcoR1 fragment including Ninj1 was then cloned upstream of IRES2-eGFP in the multiple cloning site of the murine stem cell virus pMSCVneo (Invitrogen). Retroviral vector construct $\mathrm{pMSCV}_{\text {neo-Ninj-1-IRES2eGFP }}$ was used to transduce $\mathrm{CD}^{+} \mathrm{T}$ lymphocytes. Overexpression of Ninj1 was confirmed in in vitro and ex vivo isolated cells by quantitative PCR and immunofluorescence. $T_{M B P-G F P}$ cells overexpressing Ninj1 $\left(\mathrm{T}_{\mathrm{MBP}-\mathrm{GFP} \text {-Ninj1 }}\right.$ cells) did not differ from the control $\mathrm{T}_{\mathrm{MBP}-\mathrm{GFP}}$ cells (established in parallel) in terms of antigen responsiveness, surface antigen phenotype and cytokine production.

31. Eylar, E. H., Kniskern, P. J. \& Jackson, J. J. Myelin basic proteins Methods Enzymol. 32, 323-341 (1974)

32. Ben-Nun, A., Wekerle, H. \& Cohen, I. R. The rapid isolation of clonable antigenspecific T lymphocyte lines capable of mediating autoimmune encephalomyelitis. Eur. J. Immunol. 11, 195-199 (1981).

33. Kawakami, N. et al. Autoimmune CD4+ T cell memory: lifelong persistence of encephalitogenic T cell clones in healthy immune repertoires. J. Immunol. 175, 69-81 (2005).

34. Odoardi, F. et al. Instant effect of soluble antigen on effector $T$ cells in peripheral immune organs during immunotherapy of autoimmune encephalomyelitis. Proc. Natl Acad. Sci. USA 104, 920-925 (2007).

35. Pintelon, I. etal. Selective visualisation of neuroepithelial bodies in vibratome slices of living lung by 4-Di-2-ASP in various animal species. Cell Tissue Res. 321, 21-33 (2005).

36. Huber, W., von Heydebreck, A., Sueltmann, H., Poustka, A. \& Vingron, M. Parameter estimation for the calibration and variance stabilization of microarray data. Stat. Appl. Genet. Mol. Biol. 2, article 3 (2003).

37. Irizarry, R. A. et al. Exploration, normalization, and summaries of high density oligonucleotide array probe level data. Biostatistics 4, 249-264 (2003).

38. Sturn, A., Quackenbush, J. \& Trajanoski, Z. Genesis: cluster analysis of microarray data. Bioinformatics 18, 207-208 (2002).

39. Dahlquist, K. D. et al. GenMAPP, a new tool for viewing and analyzing microarray data on biological pathways. Nature Genet. 31, 19-20 (2002)

40. Cordiglieri, C. et al. Nicotinic acid adenine dinucleotide phosphate-mediated calcium signalling in effector T cells regulates autoimmunity of the central nervous system. Brain 133, 1930-1943 (2010).

41. Reinhardt, R. L. etal. Visualizing the generation of memory CD4 T cells in the whole body. Nature 410, 101-105 (2001)

42. Araki, T. et al. Mechanism of homophilic binding mediated by ninjurin, a novel widely expressed adhesion molecule. J. Biol. Chem. 272, 21373-21380 (1997).

43. Brinkmann, V. et al. The immune modulator FTY720 targets sphingosine 1-phosphate receptors. J. Biol. Chem. 277, 21453-21457 (2002).

44. Kataoka, H. et al. FTY720, sphingosine 1-phosphate receptor modulator, ameliorates experimental autoimmune encephalomyelitis by inhibition of $\mathrm{T}$ cell infiltration. Cell. Mol. Immunol. 2, 439-448 (2005). 